\title{
IMPACTO NA ECONOMIA DAS PROPRIEDADES BANANICULTORAS EM LUÍS ALVES-SC, EM FUNÇÃO DA IMPLEMENTAÇÃO DAS ÁREAS DE PRESERVAÇÃO PERMANENTE ${ }^{1}$
}

\author{
Cirlene Kluck², Julio César Refosco ${ }^{3}$, Eder Caglioni ${ }^{4}$ e Guilherme de Almeida Armênio ${ }^{5}$
}

\begin{abstract}
RESUMO - Esta pesquisa teve por objetivo principal analisar o impacto econômico das Áreas de Preservação Permanente (APP), bem como os conflitos de uso dessas áreas em propriedades bananicultoras no Município de Luís Alves, Santa Catarina, considerando-se a implementação do Código Florestal Brasileiro (Lei 4.771/65). A base metodológica provém da economia agrícola, de técnicas de manejo de culturas agrícolas, da gestão ambiental, do sensoriamento remoto e dos sistemas de informações geográficas. Foram consideradas 15 propriedades rurais, tendo como atividade principal a ba nanicultura. Utilizou-se uma planilha para coleta de dados, localização e distribuição das áreas de atividade nas propriedades. A partir dessas informações associadas a informações de imagens de satélite, geraram-se mapas de uso do solo, de limites de propriedades e de APPs. As informações foram organizadas num Sistema de Informações Geográficas - SIG, utilizando o software ARCVIEW 9.1. As propriedades foram analisadas em três grupos (I, II e III), conforme a área de lavoura de banana e investimentos em benfeitorias, máquinas e implementos. Realizou-se uma análise de impacto econômico sobre as propriedades em função da implementação das APPs. Com a pesquisa, percebeu-se que haverá redução da renda líquida das propriedades rurais de 38,58\%, 27,65\% e 40,21\% para os Grupos I, II e III, respectivamente, com a adequação das APPs para a média das propriedades bananicultoras analisadas.
\end{abstract}

Palavras-chave: Código Florestal Brasileiro, Áreas de Preservação Permanente, Impacto econômico e Luís Alves-SC.

\section{IMPACT ON ECONOMY OF BANANA CULTIVATION FARMS IN LUÍS ALVES-SC, IN FUNCTION OF THE IMPLEMENTATION OF PERMANENT PRESERVATION AREAS}

\begin{abstract}
This research aims at analyzing the economic impact of Permanent Preservation Areas (PPA, as well as their clash with current practices on farms dedicated to banana cultivation farms located in Luís Alves, SC-Brazil, considering the enforcement of the Brazilian Forest Act (Law 4.771/65). The methodology used for this work is based on agricultural economics, crop management techniques, environmental management, remote sensing, and geographical information systems. It was considered 15 farms, whose main activity was dedicated to banana production. A spreadsheet was used for collecting data as well as localizing and defining of activities areas on the farms. From those pieces of information associated to pieces of information of satellite images, it was created maps of land use, farm boundaries and permanent preservation areas. Pieces of information were organized in the Geographical Information System by using the ARCVIEW 9.1 software. Farms were analyzed in three groups (I, II and III) according to the banana crop area and investments in facilities, machines and implements. An analysis of the economic impact on the farms in function of implementation of PPA was carried out. By this work, it was realized that there will be a reduction on the net income of the farms by $38.58 \%, 27.65 \%$ and $40.21 \%$, for the groups I, II and III, respectively, with adequation of the PPAs for the average of the banana cultivation farms analyzed.
\end{abstract}

Keywords:Brazilian Brazilian Forest Act, Economic impact, Luís Alves-SC and Permanent protected.

\footnotetext{
${ }^{1}$ Recebido em 20.09.2009 e aceito para publicação em 18.04.2011.

2 EMATER/ASCAR, RS E.M. Faxinalzinho, Brasil. E-mail: <cirlenekluck@hotmail.com>.

${ }^{3}$ Departamento de Engenharia Florestal, Fundação Universidade Regional de Blumenau, FURB, Brasil. E-mail: <julio.refosco@gmail.com> .

${ }^{4}$ Programa de Pós-Graduação em Engenharia Florestal pela Universidade Federal do Paraná/UFPR, Brasil. E-mail: <eder.ca@hotmail.com>.

${ }^{5}$ Acadêmico Engenharia Florestal, FURB, Brasil. E-mail: <guiarmenio@gmail.com>.
} 


\section{INTRODUÇÃO}

No Brasil, a problemática ambiental é tratada em vários segmentos da sociedade e o país possui ampla legislação para proteger os recursos naturais em níveis federal, estadual e municipal.

Vários trabalhos têm abordado a problemática do conflito gerado para estabelecer as Áreas de Preservação Permanente (APPs). Acerca dessas questões podem ser citados os trabalhos de Neumann e Loch (2002), Oliveira (2005) e Trentini (2004). No caso de Santa Catarina, o tamanho das propriedades rurais, alta declividade, grande densidade de cursos d’água e pedregosidade de boa parte das terras levaram à incorporação das margens dos rios como áreas produtivas, com a utilização na agricultura e na pecuária, sendo assim, fonte de renda dessas famílias.

Segundo Bley Junior et al. (2004), apesar de a legislação brasileira ser uma das mais rigorosas do mundo, não se obtém nos dias atuais o esperado desempenho na preservação do meio ambiente. Alguns de seus conteúdos são destinados a não produzir os desejados efeitos de preservação, mas, sim, estabelecer um emaranhado de critérios nem sempre sustentados cientificamente.

A gestão ambiental constitui a área de conhecimento onde se confrontam os objetivos associados ao desenvolvimento, ordenamento e aqueles voltados para a conservação da natureza ou para a preservação da qualidade ambiental, sendo introduzidas nas diversas áreas, gerenciando a natureza como um patrimônio, na dimensão de transmissão às gerações futuras.

Os instrumentos de comando e controle, voluntários, econômicos e gastos governamentais são os principais instrumentos de política ambiental pública citados por Merico (2002), que descreveu a forma de implementação dessas políticas para efetivação da gestão.

A configuração de um desenvolvimento sustentável aponta a necessidade de se criarem mecanismos e instrumentos de gestão ambiental que sejam capazes de dar respostas aos problemas expostos, em sintonia com os contextos sociais, econômicos e agroecológicos nos quais estes se manifestam adequados às diferentes categorias e atores sociais presentes no meio rural (NEUMANN, 2003).
Com o avanço das tecnologias de geomática é possível verificar imagens, coletar e registrar informações que contribuem para a gestão ambiental. Assim, as técnicas de Sensoriamento Remoto e Sistemas de Informações Geográficas (SIG) têm sido utilizadas de forma conjugada em estudos de recursos terrestres, com especial atenção para o monitoramento das atividades antrópicas e seus impactos ambientais (PINTO; LOMBARDO, 2003).

Segundo Guanziroli et al. (2001), a agricultura familiar é a principal fonte de ocupação de trabalho no meio rural brasileiro. Dos 17,3 milhões de pessoas ocupadas na agricultura brasileira, 13.780.201 estão empregados na agricultura familiar. Mesmo dispondo de apenas 30\% da área, ela é responsável por 79,6\% do pessoal ocupado.

No Município de Luís Alves, SC, situado no vale do Itajaí, a $140 \mathrm{~km}$ de Florianópolis, existe a predominância da pequena propriedade, caracterizada por áreas menores que 30 ha. A maior parte da população está envolvida em atividades agrícolas e a bananicultura contribui significativamente para a economia do município.

Segundo Souza e Conceição (2002), em Santa Catarina a bananeira é a principal frutífera em área cultivada e tem grande importância social em cerca de 5.000 estabelecimentos agrícolas, onde é a principal fonte de renda.

Observou-se, assim, a importância de estudar a produção bananicultora em APPs, especialmente dos pontos de vista econômico-financeiro e ambiental, dado que parte considerável dessa cultura é realizada nessas Áreas de Preservação Permanente, que as rendas familiar e municipal dependem dessa cultura e que tem havido grande pressão para resolver os conflitos.

Esta pesquisa concentrou-se na área temática da gestão ambiental, a qual visa gerenciar os recursos naturais mediante a aplicação de diversos instrumentos, entre eles os jurídicos. O objetivo principal foi analisar o impacto econômico das Áreas de Preservação Permanente (APP), bem como os conflitos de uso dessas áreas, em propriedades bananicultoras no Município de Luís Alves, considerando-se a implementação do Código Florestal Brasileiro (Lei 4.771/65), no que diz respeito às APPs.

Revista Árvore, Viçosa-MG, v.35, n.3, Edição Especial, p.707-716, 2011 


\section{MATERIAL E MÉTODOS}

A base metodológica utilizada provém da economia agrícola, das técnicas de manejo de culturas agrícolas, da gestão ambiental e de sistemas de informações geográficas.

Nesta pesquisa foram consideradas, segundo o Código Florestal (Lei 4.771/65), as Áreas de Preservação Permanente ao longo dos rios ou qualquer curso d’água, nascentes, topos de morro e encostas com declividade superior a $45^{\circ}$.

Utilizou-se, como primeiro recorte para área de estudo, o Município de Luís Alves, SC, sendo ele bastante representativo na região onde se insere, em função da sua hidrologia, topografia e características fundiárias agrícolas. Como recorte mais específico foram selecionadas 15 propriedades agrícolas, naquele município, para implementação de um estudo mais aprofundado.

As propriedades distribuíram-se em três grupos equitativos, e os critérios utilizados para o agrupamento das propriedades foram: o tamanho da área produtiva de banana e o nível de investimentos em máquinas, equipamentos e benfeitorias. Tais critérios permitem a percepção de uma possível relação entre a intensidade do impacto econômico e o tamanho da área de lavoura de banana. Os grupos utilizados estão relacionados a seguir:

Grupo I - Área de lavoura de banana entre 30,1 e 50 ha, um galpão com 300 m²$^{2}$ duas casas para empregados, um trator $70 \mathrm{cv}$, quatro carretas para trator, um pulverizador tratorizado, quatro pulverizadores costais e uma plaina.

Grupo II - Área de lavoura de banana entre 15,1 e 30 ha, um galpão de $200 \mathrm{~m}^{2}$, um trator 65 cv, duas carretas para trator, um pulverizador tratorizado, dois pulverizadores costais e uma plaina.

Grupo III - Área de lavoura de banana até 15 ha, galpão de $150 \mathrm{~m}^{2}$, uma caminhonete pick up e três pulverizadores costais.

O Grupo I foi o que teve a maior área de lavoura de banana e investimentos em benfeitorias, máquinas e implementos, o Grupo II foi intermediário entre os dois grupos e o Grupo III representou pequenos produtores rurais com o mínimo de investimento necessário para a condução da lavoura de banana.
As propriedades analisadas foram selecionadas levando-se em consideração alguns aspectos básicos e importantes na região agrícola. Foram selecionados produtores rurais em que em suas atividades agrícolas predominam a cultura da banana como fator gerador de renda, sendo essa atividade de alta expressão econômica para o município e que supostamente gera impacto relacionado à questão estudada.

Todos os produtores considerados no levantamento estavam organizados na forma de Associação dos Bananicultores de Luís Alves (ABLA) e participaram do sistema de Produção Integrada da Banana, sendo assim considerados produtores que faziam uso de tecnologia, apresentando frutas de qualidade para garantir a competitividade nos mercados nacional e internacional, critério básico para a escolha dessas propriedades.

Na Figura 1, apresenta-se a localização da realização do estudo, bem como as propriedades estudadas. Em cada um dos recortes foi realizada uma abordagem metodológica, descrita nos parágrafos subsequentes.

Para o diagnóstico das propriedades, utilizou-se uma planilha para coleta de dados, localização e distribuição das diferentes áreas (lavoura, sede, nascentes, córregos, matas etc.), quantificando a superfície e a distribuição em termos de uso e ocupação. Foi realizada uma avaliação visual em campo das APPs nos córregos da situação atual.

Paralelamente, em laboratório, os dados foram inseridos num sistema de informações geográficas, utilizando o programa ArcGIS 9.1 e organizando um projeto de SIG para cada propriedade. Nessa etapa, tendo como base cartográfica os mapas do IBGE, realizou-se a transcrição dos dados de campo, obtidos pela planilha

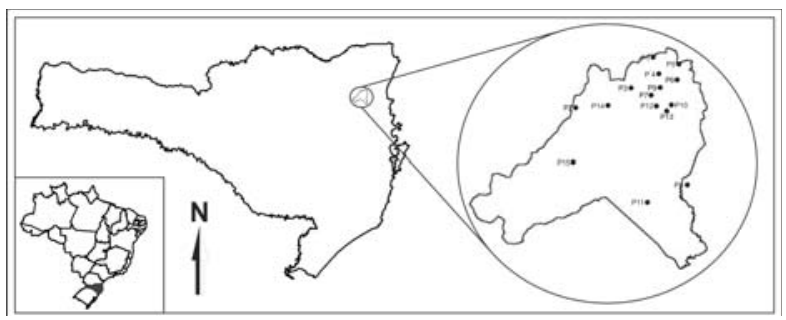

Figura 1 - Localização da área de estudo, Município de Luís Alves, em Santa Catarina, e as propriedades analisadas.

Figure 1 - Localization of the study area in Luís Alves, Santa Catarina and the analyzed farms. 
e pelos croquis, para o SIG, produzindo mapas de limites das propriedades, hidrografia e uso do solo. Os mapeamentos foram auxiliados pelo uso de imagens do sistema Google Earth, as quais foram corrigidas geometricamente através de um processo de registro com os mapas do IBGE.

As imagens de satélite utilizadas foram obtidas do sistema Google Earth versão 4.2, o qual disponibiliza imagens de sensores diversos, sendo utilizadas neste trabalho aquelas oriundas do sensor IKONOS. As cartas topográficas, hidrográficas e de limites administrativos municipais foram obtidas no Instituto Brasileiro de Geografia e Estatística (IBGE). As cartas utilizadas foram: SG-22-Z-B-IV-2, SG-22-Z-B-IV-4, SG-22-Z-B-V-1 e SG22-Z-B-V-3, em formato digital, na escala de 1:50.000 (IBGE, 1974), contendo curvas de nível com equidistância de 20 m e rede hidrográfica, além dos pontos relativos a nascentes e estradas.

Conforme Ribeiro et al. (2005), as tecnologias digitais viabilizam a delimitação automática das APPs para todo o território brasileiro, conferindo rapidez, confiabilidade e facilidade de identificação de conflitos de uso da terra usando imagens orbitais atualizadas.

Para a interpretação das imagens e confecção do mapa de uso do solo, as imagens foram tratadas no sistema ArcGIS, através de interpretação manual realizada na tela do computador. Foi utilizado um sistema de classes simplificado adequado à realização deste trabalho (cultura de banana, vegetação natural, área sede da propriedade, águas). Foram produzidos mapas de uso do solo de cada propriedade. Os limites das propriedades foram obtidos dos proprietários e desenhados em croquis que depois foram transferidos como mapas para o sistema ARGIS para possibilitar a análise desejada. Além disso, também visando à análise, foram mapeadas as Áreas de Preservação Permanentes (APPs), segundo o Código Florestal Brasileiro.

É importante enfatizar que o método utilizado não permitiu identificar faixas de APPs muito estreitas ou, mesmo, pequenas manchas de vegetação, já que não foi utilizada resolução total disponível pelas imagens. Dessa forma, estima-se que faixas menores que $3 \mathrm{~m}$ de largura não tenham sido avaliadas, o que pode levar a uma subestimativa das faixas de APPs.
Os cursos d’água das propriedades foram obtidos a partir do mapa hidrográfico do IBGE, enriquecido com informações obtidas em visitas às propriedades.

Paralelamente foi realizado um mapeamento de todo o Município de Luís Alves e utilizada a mesma base cartográfica (IBGE, 1974), na busca de conhecer melhor a situação do município quanto às APPs. Para isso, com o uso do programa ArcGIS foram realizados três mapas de APPs: margem de rios, topos de morros e encostas, conforme a legislação ${ }^{7}$. Para o mapa de APPs de margens de rios e nascentes, foi realizado um "buffer" de $30 \mathrm{~m}$ de largura em cada margem do rio (60 m no total) e $50 \mathrm{~m}$ de raio em torno de cada nascente. Para o mapa de APPs de encostas, foi feito um modelo numérico do terreno a partir do mapa de curvas de nível (equidistância de 20 em 20 m) e a partir desse um mapa de declividade do terreno, o qual foi posteriormente classificado para apresentar duas classes - declividade maior que $45^{\circ}$ e declividade menor que $45^{\circ}$. Para o mapa de APPs de topos de morros foi realizada uma análise do mapa topográfico e selecionados os morros conforme a legislação define, sendo para esses traçado o seu terço superior. Em seguida, os mapas foram unidos em um para representar APPs de forma geral.

Realizou-se uma análise de impacto econômico das propriedades bananicultoras, observando que, como alternativa, foram utilizados dados de propriedades representativas e semelhantes em nível de tecnologia, com custo de produção médio, bem como produtividade média, ao longo dos quatro últimos anos.

A metodologia de cálculo de custo de produção e a análise dos indicadores econômicos foram baseadas em Martin et al. (1998). A estrutura do custo de produção utilizada foi custo operacional de produção, que leva em consideração desembolsos efetivos realizados pelo produtor durante o ciclo produtivo, englobando despesas com mão de obra, operações com máquinas e implementos agrícolas, insumos e, ainda, o valor de depreciação dos equipamentos utilizados no processo produtivo. Assim, foram estipuladas as despesas com operações agrícolas e com material consumido, totalizando os Custos Operacionais Efetivos (COE), além de outros custos operacionais como depreciações e encargos

Legislação que define APP, Código Florestal (Lei 4.771/65).

Revista Árvore, Viçosa-MG, v.35, n.3, Edição Especial, p.707-716, 2011 
financeiros, que somados ao COE resultam no Custo Operacional Total (COT $=$ COE + depreciação + encargos). Não foram levados em consideração outros custos de oportunidade imputados à atividade produtiva que visam à remuneração do capital fixo em terra, instalações e máquinas, que somados ao COT representariam os Custos Totais de produção (CT).

Para o cálculo do custo de produção, tomou-se como base a média do custo de quatro anos consecutivos (2004 a 2007), para 1 ha de Banana-Nanicão ou Grande Naine, do grupo Cavendish, considerando-se lavoura já implantada (custo de manutenção) para as propriedades consideradas nos Grupos I, II e III, conforme área média da lavoura, benfeitorias, máquinas e implementos. Depois de levantado o custo de produção do qual foi analisado, geraram-se os indicadores econômicos, avaliando as áreas com o uso atual e as inserções das APPs, chegando, assim, aos resultados norteadores do trabalho.

Para análise econômica das propriedades, foram determinados os seguintes indicadores econômicos: Receita Bruta (produção x preço médio de venda); Receita Líquida (receita bruta menos o custo operacional total), Lucratividade (receita líquida pela receita bruta) e o Ponto de Nivelamento (custo operacional total dividido pelo preço de venda), que corresponde à quantidade de caixas de banana necessárias para cobrir os custos de produção.

\section{RESULTADOS}

A quantificação da área total das propriedades bananicultoras, a área de lavoura de banana, a lavoura de banana fora da APP e a lavoura de banana em APP são apresentadas na Tabela 1 .

Realizou-se o cálculo do custo de produção da banana para o subgrupo Cavendish, voltado a plantações comerciais no Município de Luís Alves, conforme Tabela 2, considerando os itens despesa com maquinários, melhoria de infraestrutura e depreciação com valores variáveis nos três grupos.

Na apresentação da análise econômica das propriedades (Tabela 3), o preço de venda médio foi de $\mathrm{R} \$ 4,60$ por caixa de $22 \mathrm{~kg}$, com uma produtividade de 1.409 caixas por hectare.

Na Tabela 4, como fechamento da pesquisa, apresenta-se o impacto econômico da redução das áreas de lavoura de banana das propriedades analisadas.

\section{DISCUSSÃO}

A análise da Tabela 1 demonstrou que em média, por grupo, a área total da propriedade era de 52,76 ha, 25,08 ha e 10,38 ha, e que dessa área parte era ocupada com a cultura da banana, com médias de 73,43\%, 73,12\% e $65,04 \%$ nos Grupos I, II e III, respectivamente, confirmando, assim, o predomínio da cultura de banana nas propriedades estudadas.

De acordo com a Tabela 1, a área de lavoura de banana em APP é variável entre propriedades, bem como entre grupos, indo de 3,96\% a 44,75\% de lavoura de banana em APP, contudo a média de cada um dos grupos é de 28,32\%, 19,98\% e 30,73\%, respectivamente.

Observa-se ainda, nessa tabela, que todas as propriedades bananicultoras analisadas estavam em conflito de uso com as APPs. Os valores médios encontrados são expressivos como conflitos dessas áreas, demonstrando claramente a ordem de grandeza do problema, questionado na pesquisa.

A mesma Tabela 1 demonstra que o Grupo III é aquele com menor área total de propriedade, com um percentual de lavoura de banana de $69,27 \%$ fora da APP e 30,73\% dentro da APP, considerando-se que para a adequação das APPs esse grupo perderia 1/3 de sua área produtiva. Confirma-se aqui o grande impacto da implementação das APPs em pequenas propriedades rurais, diante da necessidade de produção e das condicionantes ambientais.

De qualquer forma, essa constatação remete ao fato de que a cultura de maior renda nas propriedades analisadas será a mais impactada no caso de implementação de políticas de recuperação de APPs. Os dados indicaram que, das 15 propriedades estudadas, nenhuma se apresentou sem conflitos em APP. Ou seja, nenhuma das propriedades cumpre atualmente o que preconiza a legislação.

Jacovine et al. (2008) realizaram trabalho de identificação e quantificação das APPs em propriedades da bacia do rio Pomba, em Minas Gerais, região caracterizada por relevo montanhoso e com marcante presença de nascentes e cursos d’água. Observaram que todas as 47 propriedades estudadas estavam em desacordo com a lei, no que diz respeito às APPs.

Em relação ao custo de produção, os itens considerados como relevantes são fertilizantes, mão de obra e depreciação. Esses três itens apenas 
Tabela 1 - Resumo das informações sobre lavoura de banana Cavendish e APPs nas propriedades estudadas.

Table 1 - Information summary on banana Cavendish farm and permanent protected areas on the farms studied.

\begin{tabular}{|c|c|c|c|c|c|c|c|c|}
\hline \multirow[t]{2}{*}{ Grupo } & \multirow[t]{2}{*}{ Propriedade } & \multirow[t]{2}{*}{$\begin{array}{c}\text { Área total da } \\
\text { propriedade (ha) }\end{array}$} & \multicolumn{2}{|c|}{ Lavoura de banana } & \multicolumn{2}{|c|}{$\begin{array}{c}\text { Lavoura de banana } \\
\text { fora da APP }\end{array}$} & \multicolumn{2}{|c|}{$\begin{array}{c}\text { Lavoura de banana } \\
\text { em APP }\end{array}$} \\
\hline & & & (ha) & $(\%)$ & (ha) & $(\%)$ & (ha) & $(\%)$ \\
\hline \multirow{6}{*}{ I } & P 1 & 73,83 & 46,68 & 63,22 & 35,69 & 76,46 & 10,99 & 23,54 \\
\hline & P 2 & 46,47 & 43,94 & 94,56 & 30,72 & 69,92 & 13,22 & 30,08 \\
\hline & P 3 & 39,77 & 35,85 & 90,16 & 22,89 & 63,86 & 12,96 & 36,14 \\
\hline & P 4 & 59,26 & 31,51 & 53,18 & 17,41 & 55,25 & 14,10 & 44,75 \\
\hline & P 5 & 44,48 & 29,37 & 66,02 & 27,29 & 92,93 & 2,08 & 7,07 \\
\hline & Média & 52,76 & 37,47 & 73,43 & 26,80 & 71,68 & 10,67 & 28,32 \\
\hline \multirow{5}{*}{ II } & P 6 & 25,27 & 22,13 & 87,58 & 18,13 & 81,94 & 4,00 & 18,06 \\
\hline & P 7 & 30,50 & 19,24 & 63,08 & 11,32 & 58,86 & 7,91 & 41,14 \\
\hline & P 8 & 21,76 & 17,47 & 80,27 & 16,77 & 96,04 & 0,69 & 3,96 \\
\hline & P 9 & 28,17 & 16,19 & 57,46 & 13,06 & 80,68 & 3,13 & 19,32 \\
\hline & P 10 & 19,73 & 15,23 & 77,19 & 12,58 & 82,61 & 2,65 & 17,39 \\
\hline \multirow{7}{*}{ III } & Média & 25,08 & 18,05 & 73,12 & 14,37 & 80,02 & 3,68 & 19,98 \\
\hline & P 11 & 12,41 & 9,38 & 75,56 & 5,69 & 60,65 & 3,69 & 39,35 \\
\hline & P 12 & 11,71 & 9,21 & 78,63 & 5,44 & 59,11 & 3,77 & 40,89 \\
\hline & P 13 & 13,50 & 6,26 & 46,34 & 5,79 & 92,48 & 0,47 & 7,52 \\
\hline & P 14 & 6,50 & 6,02 & 92,62 & 4,24 & 70,47 & 1,78 & 29,53 \\
\hline & P 15 & 7,77 & 2,49 & 32,04 & 1,58 & 63,61 & 0,91 & 36,39 \\
\hline & Média & 10,38 & 6,67 & 65,04 & 4,55 & 69,27 & 2,12 & 30,73 \\
\hline
\end{tabular}

correspondem a aproximadamente $60 \%$ do custo total de produção nos três grupos, tanto em área atual quanto em área de lavoura considerando APPs.

A mão de obra necessária para a condução da lavoura de banana corresponde a um percentual de 23\% do custo de produção. Sendo significativo em relação ao custo total, esse fato se deve às técnicas de manejo adotadas (desbaste, desfolha, poda de pencas, poda do coração, escoramento das plantas, adubação química, adubação orgânica, calagem, controle de pragas e doenças, ensacamento dos cachos, colheita e transporte).

Outro fator que contribui para a demanda de mão de obra é a topografia das propriedades, que não comportam tecnologias de transporte da fruta, fazendo que a bananicultura necessite de mão de obra tanto para condução da lavoura quanto para o beneficiamento da fruta. Considerando o caso da implementação das APPs, essa mão de obra estaria comprometida.

Ressalta-se, com isso, que a cultura da banana é caracterizada como predominantemente de uso intensivo de mão de obra, evidenciando com isso a importância social, geração de emprego e renda. Não só de forma direta, mas indiretamente gerando postos de trabalho e fixando um contingente de famílias, promovendo o desenvolvimento do município e da região.
No que se refere ao custo de lavoura, conforme Tabela 2, no item depreciação (que considera benfeitorias, máquinas e implementos), o Grupo I, no uso atual com lavoura de banana (lavoura incluindo APP), representa 8,77\%, e com a implementação das APPs (lavoura excluindo APP) esse percentual aumenta para $11,85 \%$; contudo, a diferença é maior no Grupo III, onde para o uso atual é de 9,57\% e, com a implementação das APPs, passa para 13,43\%, embora a quantidade de área reduzida seja maior no Grupo I (média de 37,47 ha para 26,80 ha), e o maior percentual de depreciação encontra-se no Grupo III.

Na Tabela 2 e considerando a perda de área média dos Grupos I, II e III, conforme Tabela 1 (37,47 ha para 26,80 ha; 18,05 ha para 14,37 ha; e 6,67 ha para 4,55 ha, respectivamente), identificou-se que o Grupo I perde maior quantidade de área em produção quando comparado com a área do Grupo III (menor área de produção), porém o impacto na depreciação émaior (maior custo de depreciação) no Grupo III, com a readequação das APPs, haja vista que as benfeitorias, máquinas e implementos serão mantidos.

Em relação aos indicadores econômicos, conforme Tabela 3, os índices de lucratividade para os grupos estudados, considerando as áreas atuais de produção (lavoura incluindo APP), ficaram em torno de 19,61\% a 
Tabela 2 - Custo (R\$) por hectare de lavoura de banana Cavendish, Luís Alves, março de 2008. Table 2 - Cost (R\$) per hectare for banana farming Cavendish, Luís Alves, march of 2008.

\begin{tabular}{|c|c|c|c|c|c|c|c|c|c|c|c|c|}
\hline \multirow[t]{3}{*}{ DESCRIÇÃO } & \multicolumn{4}{|c|}{ Grupo - I } & \multicolumn{4}{|c|}{ Grupo - II } & \multicolumn{4}{|c|}{ Grupo - III } \\
\hline & \multicolumn{2}{|c|}{$\begin{array}{c}\text { Lavoura } \\
\text { incluindo APP }\end{array}$} & \multicolumn{2}{|c|}{$\begin{array}{c}\text { Lavoura } \\
\text { excluindo APP }\end{array}$} & \multicolumn{2}{|c|}{$\begin{array}{l}\text { Lavoura } \\
\text { incluindo APP }\end{array}$} & \multicolumn{2}{|c|}{$\begin{array}{c}\text { Lavoura } \\
\text { excluindo APP }\end{array}$} & \multicolumn{2}{|c|}{$\begin{array}{c}\text { Lavoura } \\
\text { incluindo APP }\end{array}$} & \multicolumn{2}{|c|}{$\begin{array}{c}\text { Lavoura } \\
\text { excluindo APP }\end{array}$} \\
\hline & Valor & $\%$ & Valor & $\%$ & Valor & $\%$ & Valor & $\%$ & Valor & $\%$ & Valor & $\%$ \\
\hline ntes & $1.344,62$ & 25,81 & $1.344,62$ & 24,94 & $1.344,62$ & 26,61 & $1.344,62$ & 25,91 & $1.344,62$ & 27,50 & $1.344,62$ & 26,33 \\
\hline Fungicidas & 259,96 & 4,99 & 259,96 & 4,82 & 259,96 & 5,14 & 259,96 & 5,01 & 259,96 & 5,32 & 259,96 & 5,09 \\
\hline Óleo mineral & 98,85 & 1,90 & 98,85 & 1,83 & 98,85 & 1,96 & 98,85 & 1,90 & 98,85 & 2,02 & 98,85 & 1,94 \\
\hline Espalhante & 6,57 & 0,13 & 6,57 & 0,12 & 6,57 & 0,13 & 6,57 & 0,13 & 6,57 & 0,13 & 6,57 & 0,13 \\
\hline Inseticida & 1,00 & 0,02 & 1,00 & 0,02 & 1,00 & 0,02 & 1,00 & 0,02 & 1,00 & 0,02 & 1,00 & 0,02 \\
\hline Herbicida & 40,36 & $0,7 \overline{7}$ & 40,36 & 0,75 & 40,36 & 0,80 & 40,36 & 0,78 & 40,36 & 0,83 & 40,36 & 0,79 \\
\hline $\begin{array}{l}\text { Saco proteção } \\
\text { do cacho }\end{array}$ & 171,01 & 3,28 & 171,01 & 3,17 & 171,01 & 3,38 & 171,01 & 3,29 & 171,01 & 3,50 & 171,01 & 3,35 \\
\hline Espuma & 11,28 & 0,22 & 11,28 & 0,21 & 11,28 & 0,22 & 11,28 & 0,22 & 11,28 & 0,23 & 11,28 & 0,22 \\
\hline $\begin{array}{l}\text { Fitas para } \\
\text { escoramento }\end{array}$ & 136,68 & 2,62 & 136,68 & 2,53 & 136,68 & 2,70 & 136,68 & 2,63 & 136,68 & 2,80 & 136,68 & 2,68 \\
\hline $\begin{array}{l}\text { Aplicação } \\
\text { aérea de } \\
\text { defensivos }\end{array}$ & 353,75 & 6,79 & 353,75 & 6,56 & 353,75 & 7,00 & 353,75 & 6,82 & 353,75 & 7,24 & 353,75 & 6,93 \\
\hline $\begin{array}{l}\text { Despesa com } \\
\text { maquinários }\end{array}$ & 292,49 & 5,61 & 292,49 & 5,42 & 204,74 & 4,05 & 204,74 & 3,94 & 146,25 & 2,99 & 146,25 & 2,86 \\
\hline Mão de obra 1 & $1.217,19$ & 23,36 & $1.217,19$ & 22,57 & $1.217,19$ & 24,09 & $1.217,19$ & 23,45 & $1.217,19$ & 24,90 & $1.217,19$ & 23,84 \\
\hline Ferramentas & 35,32 & 0,68 & 35,32 & 0,65 & 35,32 & 0,70 & 35,32 & 0,68 & 35,32 & 0,72 & 35,32 & 0,69 \\
\hline $\begin{array}{l}\text { Eq. de proteção } \\
\text { individual }\end{array}$ & йо 6,61 & 0,13 & 6,61 & 0,12 & 6,61 & 0,13 & 6,61 & 0,13 & 6,61 & 0,14 & 6,61 & 0,13 \\
\hline $\begin{array}{l}\text { Melhoria de } \\
\text { infraestrutura }\end{array}$ & 232,71 & 4,47 & 32,71 & 4,32 & 87,26 & 1,73 & 87,26 & 1,68 & 46,54 & 0,95 & 46,54 & 0,91 \\
\hline Diversos & 219,07 & 4,20 & 219,07 & 4,06 & 219,07 & 4,33 & 219,07 & 4,22 & 219,07 & 4,48 & 219,07 & 4,29 \\
\hline Depreciação & 457,08 & 8,77 & 639,05 & 11,85 & 533,52 & 10,56 & 670,15 & 12,91 & 467,77 & 9,57 & 685,71 & 13,43 \\
\hline $\begin{array}{l}\text { Subtotal } \\
\text { Encargos }\end{array}$ & $\begin{array}{c}\mathbf{4 . 8 8 4 , 5 5} \\
325,88\end{array}$ & $\begin{array}{c}93,75 \\
6,25\end{array}$ & $\begin{array}{c}\mathbf{5 . 0 6 6 , 5 3} \\
325,88\end{array}$ & $\begin{array}{c}93,96 \\
6,04\end{array}$ & $\begin{array}{c}4.727,79 \\
325,88\end{array}$ & $\begin{array}{c}93,55 \\
6,45\end{array}$ & $\begin{array}{c}\mathbf{4 . 8 6 4 , 4 2} \\
325,88\end{array}$ & $\begin{array}{c}93,72 \\
6,28\end{array}$ & $\begin{array}{c}\mathbf{4 . 5 6 2 , 8 3} \\
325,88\end{array}$ & $\begin{array}{c}93,33 \\
6,67\end{array}$ & $\begin{array}{c}\mathbf{4 . 7 8 0 , 7 8} \\
325,88\end{array}$ & $\begin{array}{c}93,62 \\
6,38\end{array}$ \\
\hline Subtotal & 325,88 & 6,25 & 325,88 & 6,04 & 325,88 & 6,45 & 325,88 & 6,28 & 325,88 & 6,67 & 325,88 & 6,38 \\
\hline TOTAL & $5.210,42$ & 100,00 & $5.392,40$ & 100,00 & $5.053,66$ & 100,00 & $5.190,29$ & 100,00 & $4.888,70$ & 100,00 & $5.106,65$ & 100,00 \\
\hline
\end{tabular}

24,57\%, e com a implementação das APPs (lavoura excluindo APP) essa lucratividade caiu para $16,80 \%$ a $21,21 \%$ por hectare. É importante destacar que a maior perda de lucratividade ocorreu no Grupo III, ou seja, pequenas áreas produtivas tiveram sua renda mais comprometida (diminuição da produção com menor renda bruta e aumento da depreciação com redução da renda líquida).

Também na Tabela 3, pode-se observar que, com a redução da área de lavoura, o custo operacional total aumentou, pois a depreciação foi reformulada, a produção diminuiu e, consequentemente, a renda bruta e a renda líquida também.

Conforme apresentado na Tabela 4, analisando o impacto econômico das propriedades amostradas em termos médios, observou-se no Grupo I redução de área da lavoura de banana de 28,32\%, gerando, assim, queda na renda líquida de 38,58\%, devido ao aumento do custo. No Grupo II, tem-se a diminuição da área de lavoura de $20,00 \%$ e 27,65\% de renda líquida e no
Grupo III, reduções na área de lavoura de 30,73\% e 40,21\% da renda líquida, comprovando, assim, o impacto econômico negativo nas propriedades estudadas, sendo mais relevante nas pequenas propriedades.

A importância dessa análise está em comprovar o impacto econômico negativo gerado nas propriedades em conflito, entre os interesses individuais dos proprietários rurais e os interesses coletivos de proteger o ambiente e a necessidade de estratégias no emprego dos instrumentos de gestão ambiental para a condução da solução do conflito.

\section{CONCLUSÃO}

Com o final da pesquisa, a apresentação dos resultados e sua análise, podem ser citadas algumas conclusões, conforme se segue:

Apesar da importância das APPs, todas as propriedades analisadas apresentavam conflito de uso do solo nas APPs.

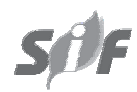

Revista Árvore, Viçosa-MG, v.35, n.3, Edição Especial, p.707-716, 2011 
Nesta pesquisa, percebeu-se que a média das propriedades bananicultoras analisadas teria, com a implementação das APPs, reduções na área de lavoura médias de 28,32\%, 20,00\% e 30,73\%, conforme os Grupos I, II e III estudados.

Nesse mesmo sentido, a renda líquida das propriedades rurais com a adequação das APPs teria reduções de 38,58\%, 27,65\% e 40,21\%, nos Grupos I, II e III, respectivamente.

O cumprimento da legislação de APPs geraram impacto muito significativo nas propriedades rurais analisadas, a ponto de inviabilizá-las na forma atual de produção, sendo essa questão mais crítica quanto menor era a área da propriedade.

A manutenção das APPs, contudo, ao longo do tempo, produz benefícios ambientais que ultrapassaram os limites de uma propriedade agrícola, afetando toda a sociedade de forma positiva em curto, médio e longo prazos. Apesar disso, a implementação das APPs tem consequências econômicas e sociais negativas no curto prazo, principalmente nas propriedades agrícolas, o que justificaria um bônus ou uma valoração financeira pelo benefício ambiental proporcionado a toda a sociedade, de forma que o produtor rural não fosse excluído do processo produtivo.

A Gestão Ambiental propõe instrumentos de política ambiental. Em razão da possibilidade de inviabilização econômica das propriedades, há forte indicação da necessidade de outros instrumentos e mais articulados (educação ambiental, instrumentos econômicos como preservador recebedor), mais complexos de tratamento da questão das APPs do que os simples instrumentos de comando e controle. Assim, é recomendado que esta pesquisa possa ser ampliada para outras atividades agrícolas e para outras regiões do Estado de Santa Catarina.

Tabela 3 - Indicadores econômicos para a bananicultura, no Município de Luís Alves.

Table 3 - Economics indicators for banana farming, Luís Alves city.

\begin{tabular}{lccc}
\hline GRUPO I & & & \\
Descrição & Unid. & Lavoura incluindo APP & Lavoura excluindo APP \\
\hline Custo Operacional Total/ha - COT & $\mathrm{R} \$$ & $5.210,42$ & $5.392,40$ \\
Produção - PROD & cx $22 \mathrm{~kg}$ & $1.409,00$ & $1.409,00$ \\
Preço de Venda - PV & $\mathrm{R} \$$ & 4,60 & 4,60 \\
Renda Bruta - RB & $\mathrm{R} \$$ & $6.481,40$ & $6.481,40$ \\
Renda Líquida - RL & $\mathrm{R} \$$ & $1.270,98$ & $1.089,00$ \\
Lucratividade - LUC & $\%$ & 19,61 & 16,80 \\
Ponto de Nivelamento & cx $22 \mathrm{~kg}$ & $1.132,70$ & $1.172,26$ \\
\hline GRUPO II & & & Lavoura excluindo APP \\
Descrição & Unid. & Lavoura incluindo APP & $5.190,29$ \\
Custo Operacional Total/ha - COT & $\mathrm{R} \$$ & $5.053,66$ & $1.409,00$ \\
Produção - PROD & cx $22 \mathrm{~kg}$ & $1.409,00$ & 4,60 \\
Preço de Venda - PV & $\mathrm{R} \$$ & 4,60 & $6.481,40$ \\
Renda Bruta - RB & $\mathrm{R} \$$ & $6.481,40$ & $1.291,11$ \\
Renda Líquida - RL & $\mathrm{R} \$$ & $1.427,74$ & 19,92 \\
Lucratividade - LUC & $\%$ & 22,03 & $1.128,32$ \\
Ponto de nivelamento & cx $22 \mathrm{~kg}$ & $1.098,62$ & \\
\hline GRUPO III & & & Lavoura excluindo APP \\
Descrição & Unid. & Lavoura incluindo APP & $5.106,65$ \\
\hline Custo Operacional Total/ha - COT & $\mathrm{R} \$$ & $4.888,70$ & $1.409,00$ \\
Produção - PROD & cx $22 \mathrm{~kg}$ & $1.409,00$ & 4,60 \\
Preço de Venda - PV & $\mathrm{R} \$$ & 4,60 & $6.481,40$ \\
Renda Bruta - RB & $\mathrm{R} \$$ & $6.481,40$ & $1.374,75$ \\
Renda Líquida - RL & $\mathrm{R} \$$ & $1.592,70$ & 21,21 \\
Lucratividade - LUC & $\%$ & 24,57 & $1.110,14$ \\
Ponto de nivelamento & cx $22 \mathrm{~kg}$ & $1.062,76$ & \\
\hline
\end{tabular}

Nota: COT - Custo Operacional Total (ha); PROD - Produção, área em ha multiplicado pela produtividade de 1.409 caixas por ha.; PV - Preço de Vendas; RB - Renda Bruta (PROD * PV); RL - Renda Líquida (RB - COT); LUC - Lucratividade (RL/RB); e PN - Ponto de Nivelamento (COT/PV).

Revista Árvore, Viçosa-MG, v.35, n.3, Edição Especial, p.707-716, 2011 
Tabela 4 - Impacto econômico da redução das áreas de lavoura de banana das propriedades analisadas. Table 4 - Economic impact of reduction of areas of banana farming on analyzed properties.

\begin{tabular}{|c|c|c|c|c|c|c|c|}
\hline \multirow[b]{2}{*}{ Grupo } & \multirow[b]{2}{*}{ Prop. } & \multicolumn{2}{|c|}{ Área de produção (ha) } & \multicolumn{2}{|c|}{ Renda líquida ( $\mathrm{R} \$$ ) } & \multirow[b]{2}{*}{$\begin{array}{c}\text { Redução da área } \\
\text { de lavoura (\%) }\end{array}$} & \multirow[b]{2}{*}{$\begin{array}{l}\text { Redução da } \\
\text { renda líquida }\end{array}$} \\
\hline & & $\begin{array}{c}\text { Lavoura } \\
\text { incluindo APP }\end{array}$ & $\begin{array}{c}\text { Lavoura } \\
\text { excluindo APP }\end{array}$ & $\begin{array}{c}\text { Lavoura } \\
\text { incluindo APP }\end{array}$ & $\begin{array}{c}\text { Lavoura } \\
\text { excluindo APP }\end{array}$ & & \\
\hline \multirow{6}{*}{ I } & P 1 & 46,68 & 35,69 & $59.329,21$ & $38.866,38$ & 23,54 & 34,49 \\
\hline & P 2 & 43,94 & 30,72 & $55.846,73$ & $33.454,05$ & 30,09 & 40,10 \\
\hline & P 3 & 35,85 & 22,89 & $45.564,52$ & $24.927,19$ & 36,15 & 45,29 \\
\hline & P 4 & 31,51 & 17,41 & $40.048,48$ & $18.959,47$ & 44,75 & 52,66 \\
\hline & P 5 & 29,37 & 27,29 & $37.328,59$ & $29.718,78$ & 7,08 & 20,39 \\
\hline & Média & 37,47 & 26,80 & $47.623,51$ & $29.185,17$ & 28,32 & 38,58 \\
\hline \multirow{5}{*}{ II } & P 6 & 22,13 & 18,13 & $31.595,79$ & $23.407,78$ & 18,08 & 25,91 \\
\hline & P 7 & 19,24 & 11,32 & $27.469,64$ & $14.615,34$ & 41,16 & 46,79 \\
\hline & P 8 & 17,47 & 16,77 & $24.942,54$ & $21.651,87$ & 4,01 & 13,19 \\
\hline & P 9 & 16,19 & 13,06 & $23.115,04$ & $16.861,87$ & 19,33 & 27,05 \\
\hline & P 10 & 15,23 & 12,58 & $21.744,42$ & $16.242,13$ & 17,40 & 25,30 \\
\hline \multirow{7}{*}{ III } & Média & 18,05 & 14,37 & $25.773,49$ & $18.555,80$ & 20,00 & 27,65 \\
\hline & P 11 & 9,38 & 5,69 & $14.934,76$ & $7.818,39$ & 39,35 & 47,65 \\
\hline & P 12 & 9,21 & 5,44 & $14.665,50$ & $7.482,05$ & 40,89 & 48,98 \\
\hline & P 13 & 6,26 & 5,79 & $9.968,01$ & $7.957,35$ & 7,52 & 20,17 \\
\hline & P 14 & 6,02 & 4,24 & $9.593,10$ & $5.835,37$ & 29,53 & 39,17 \\
\hline & P 15 & 2,49 & 1,58 & $3.965,73$ & $2.177,56$ & 36,39 & 45,09 \\
\hline & Média & 6,67 & 4,55 & $10.625,42$ & $6.254,14$ & 30,73 & 40,21 \\
\hline
\end{tabular}

Para efeitos da função ambiental das Áreas de Preservação Permanente, prevista no Código Florestal Brasileiro, recomenda-se estudo mais aprofundado, a fim de comprovar a necessidade das larguras de faixas exigidas pela legislação.

\section{REFERÊNCIAS}

BLEY JUNIOR, C. et al. Código Florestal Brasileiro: considerações sobre o artigo segundo e dezesseis. In: CONGRESSO CADASTRO TÉCNICO MULTIFINALITÁRIO E GESTÃO TERRITORIAL, 2004, Florianópolis. COBRAC 2004. Florianópolis: Lab FSG, 2004. v.1. p.1050-1070.

BRASIL. Lei ${ }^{\circ}$ 4.771, de 15 de setembro de 1965. Institui o novo Código Florestal Brasileiro. Diário Oficial da República Federativa do Brasil. Brasília: 1965.

GUANZIROLI, C. et al. Agricultura familiar e reforma agrária no século XXI. Rio de Janeiro: Garamond, 2001.
INSTITUTO BRASILEIRO DE GEOGRAFIA E ESTATÍSTICA - IBGE. - Dados 1974. Disponível em: <http://www.ibge.br>. Acesso em: 29 set. 2006.

JACOVINE, L. A. G. et al. Quantificação das áreas de preservação permanente e de reserva legal em propriedades da bacia do Rio Pomba-MG.

Revista Árvore, v.2, n.32, p.269-278, 2008.

MARTIN, N. B. et al. Sistema “CUSTAGRI”: sistema integrado de custo agropecuário. Informações Agronômicas, v.28, n.1, p.7-28, 1998.

MERICO, L. F. K. Introdução à economia ecológica. 2.ed. Blumenau: Edifurb, 2002. 129p.

NEUMANN, P. S. O impacto da fragmentação e do formato das terras nos sistemas familiares de produção. 2003. Disponível em: <http://teses.eps.ufsc.br/ Resumo.asp?4351>. Acesso: 01 fev. 2006.

NEUMANN, P. S.; LOCH, C. Legislação ambiental, desenvolvimento rural e práticas agrícolas. Revista Ciência Rural, v.32, n.2, p.1-10, 2002. Disponível em: <http://www.scielo.br/ scielo>. Acesso em: 01 set. 2006. 
OLIVEIRA, A. M. S. Impacto econômico da implantação de Áreas de Preservação Permanente na Bacia do Rio Alegre, município de Alegre-ES. 2005. 62f. Tese (Magister Scientiae em Ciência Florestal) - Universidade Federal de Viçosa, Viçosa, MG, 2005.

PINTO, S. A. F.; LOMBARDO, M. O uso do sensoriamento remoto e sistemas de informações geográficas no mapeamento e uso do solo e erosão do solo. In: CONGRESSO BRASILEIRO DE CARTOGRAFIA, 12., 2003, Belo Horizonte. Anais... Belo Horizonte: 2003.
RIBEIRO, C. A. A. S. et al. O desafio da delimitação de áreas de preservação permanente. Revista Árvore, v.29, n.2, p.203-212, 2005.

SOUZA, A. T.; CONCEIÇÃO, O. A. Fatores que afetam a qualidade da banana na agricultura familiar catarinense.

Florianópolis: Instituto Cepa/SC, 2002.68p.

TRENTINi, É. C. Agricultura “Criminosa”: atividades agrícolas avaliadas à luz do Código Florestal de 1965. 2004. 123f. Dissertação

(Mestrado em Agroecossistemas) - Universidade Federal de Santa Catarina, Florianópolis, 2004. 